\title{
Short-Term Quetiapine Treatment Alters the Use of Reinforcement Signals during Risky Decision-Making and Promotes the Choice of Negative Expected Values in Healthy Adult Males
}

\author{
Philippa L. Rock, ${ }^{1}$ Catherine J. Harmer, ${ }^{1}$ Sarah F. B. McTavish, ${ }^{1}$ Guy M. Goodwin, ${ }^{1}$ and Robert D. Rogers ${ }^{2}$ \\ ${ }^{1}$ Department of Psychiatry, University of Oxford, Warneford Hospital, Oxford, OX3 7JX, United Kingdom, and ${ }^{2}$ School of Psychology, Bangor University, \\ Adeilad Brigantia, Bangor, Gwynedd, LL57 2AS, United Kingdom
}

\begin{abstract}
Effective decision-making can involve using environmental signals about the possible good and bad outcomes, and their probabilities, to select optimal actions. Problematic decision-making in psychiatric disorders, and particularly bipolar illness, may result from disrupted use of these reinforcement cues, leading to actions that reflect or precipitate pathological changes in mood. Previous experiments indicate that the processing of reinforcement cues while selecting between risky actions can be influenced by dopamine and serotonin activity. Quetiapine is an atypical antipsychotic agent with a complex pharmacology, including antagonist actions at $5-\mathrm{HT}_{2 \mathrm{~A}}$ and, to a lesser extent, $\mathrm{D}_{2}$ receptors. Here, we investigated the effects of (short-term) treatment with quetiapine on the risky decision-making of healthy human adults. Twenty participants received $150 \mathrm{mg}$ of quetiapine XL for $7 \mathrm{~d}$, whereas 20 age- and IQ-matched participants received a placebo. On the eighth day, all participants completed a risky decision-making task that involved making a series of choices between two simultaneously presented gambles that differed in the magnitudes of their possible gains and losses, and the probabilities with which these outcomes were delivered. Quetiapine treatment was associated with a marked tendency to choose options with negative expected values compared with placebo treatment in male but not female participants. Our results demonstrate that antagonism of serotonin and dopamine receptor activity can alter the way individuals use information about gains and losses when selecting between risky actions, possibly reflecting gender-specific differences in risk attitudes. These effects may be beneficial by correcting decision-making biases that feature in mood disorders.
\end{abstract}

\section{Introduction}

Monoamine neuromodulation supports decision-making by mediating critical computations of action-outcome relationships (Montague et al., 2004; Rogers, 2010; Boureau and Dayan, 2011; Cools et al., 2011). Dopamine and serotonin appear to play opposing, or at least complementary, roles in reinforcement learning and action selection (Daw et al., 2002; Boureau and Dayan, 2011). Although activity of mid-brain dopamine neurones represents the reward value of candidate actions and acts to signal discrepancies between their expected and received outcomes in the form of positive and negative prediction errors (Hollerman and Schultz, 1998; Bayer and Glimcher, 2005; Schultz, 2010), activity of the serotonergic neurones in the dorsal raphe may signal prediction errors about aversive outcomes that

Received Nov. 4, 2011; revised Aug. 17, 2013; accepted Aug. 19, 2013

Author contributions: P.L.R., C.J.H., G.M.G., and R.D.R. designed research; P.L.R. and S.F.B.M. performed research;P.L.R. and R.D.R. analyzed data; P.L.R., C.J.H., G.M.G., and R.D.R. wrote the paper.

This work was supported by the Medical Research Council, United Kingdom.

The authors declare no competing financial interests.

Correspondence should be addressed to Dr. Robert D. Rogers, School of Psychology, Bangor University, Adeilad Brigantia, Bangor, Gwynedd, LL57 2AS, United Kingdom. E-mail: r.rogers@bangor.ac.uk.

DOI:10.1523/JNEUROSCI.5721-11.2013

Copyright $@ 2013$ the authors $\quad 0270-6474 / 13 / 3315588-08 \$ 15.00 / 0$ facilitate the inhibition of ongoing behavior (Dayan and Huys, 2008; Crockett et al., 2009).

Notwithstanding the promise of these models for understanding the contribution of dopamine and serotonin to action-value learning, much less is known about how these systems influence the processing of explicit reinforcement signals when choosing between actions with uncertain outcomes. Both dopaminergic and serotonergic mechanisms play significant roles in the coding of incentive salience of environmental signals (Berridge and Robinson, 1998; Cunningham et al., 2011) and in the control of behavioral responses to incentive values (McClure et al., 2003; Berridge and Aldridge, 2008; Cunningham et al., 2010). Disruption of these systems may also play a significant role in the altered processing of environmental signals in certain psychiatric disorders, including, for example, psychosis (Roiser et al., 2009), the bipolar disorders (Abler et al., 2007; Chandler et al., 2009), and substance misuse conditions (Robinson and Berridge, 1993). Learning more about how monoamine activity influences the use of explicit reinforcement cues could facilitate the development of hypotheses about the dopaminergic and serotonergic mechanisms that contribute to faulty action selection in psychopathology, and help to identify sources of vulnerability for psychological disorders and mechanisms of therapeutic efficacy. 
Quetiapine has been shown to stabilize mood from any index episode of bipolar disorder (Bowden et al., 2005) and is effective as an adjunctive antidepressant treatment for unipolar depression (Calabrese et al., 2005; Bauer et al., 2009). Its pharmacology involves dual antagonism at $5-\mathrm{HT}_{2 \mathrm{~A}}$ and $\mathrm{D}_{2}$ receptors, and its active metabolite, norquetiapine, is also an antagonist at $5-\mathrm{HT}_{2 \mathrm{C}}$ receptors, a partial agonist at 5- $\mathrm{HT}_{1 \mathrm{~A}}$ receptors, and a noradrenaline reuptake inhibitor (Pira et al., 2004). These properties, individually or in combination, may be linked to blunted behavioral responses to powerful rewards, such as cocaine (Gallo et al., 2010), and may contribute to quetiapine's efficacy in the treatment of mood disorder (Bauer et al., 2009). Here, we investigated the effects of a short-term $7 \mathrm{~d}$ treatment with quetiapine on risky decision-making in healthy adults. We show that $7 \mathrm{~d}$ quetiapine treatment increases the frequency of action selections with negative expected value outcomes, but especially so in male compared with female participants.

\section{Materials and Methods}

Subjects. The experiment was approved by the Oxfordshire Research Ethics Committee (09/H0605/46). Volunteers were recruited using advertisements posted online and in university departments. All participants gave written informed consent.

Forty healthy adults ( 20 male and 20 female; $18-42$ years of age) took part. They were screened to exclude those with a current or previous psychiatric disorder (assessed with the Mini International Neuropsychiatric Interview-Plus) (Sheehan et al., 1998), significant physical illness, pregnancy (assessed with a pregnancy test at baseline) or lactation, current medication (except contraception), and first-degree relatives with a history of bipolar disorder or schizophrenia. Verbal IQ was assessed with the National Adult Reading Test (Nelson, 1982).

Design. The study consisted of a between-subject, double-blind, placebo-controlled design. Twenty participants (11 male, 9 female) received $150 \mathrm{mg}$ of quetiapine XL (titrated in $50 \mathrm{mg}$ steps over $3 \mathrm{~d}$ ), and 20 participants ( 9 male, 11 female) received a matched placebo (with shamtitration) at 9 P.M. for $7 \mathrm{~d}$. We chose a $7 \mathrm{~d}$ intervention because antidepressant treatment of comparable durations produces changes in the processing of social cues in healthy adults (Harmer et al., 2004). On the eighth study day, participants attended the laboratory at 1 P.M. and completed the risky choice task as part of a battery of tasks that included tests of emotion recognition, emotional categorization and memory, attentional orienting, and emotion-potentiated startle. These data are not presented here.

Psychometric assessments of subjective state. Participants completed the state versions of the Positive and Negative Affect Schedule (Watson et al., 1988), the State-Trait Anxiety Inventory (Spielberger et al., 1970), and the Befindlichkeit Scale of Mood and Energy (von Zerssen et al., 1974) at baseline and on the eighth day (Table 1).

Risky decision-making task. On each trial, participants chose between two simultaneously presented gambles. Each gamble was visually represented by a histogram, the height of which indicated the probability of gaining a given number of points (Fig. $1 A$ ). Its possible gains were indicated in green ink above the histogram, and its possible losses were indicated in red ink below the histogram. One gamble (colored yellow) served as the control gamble and always had a 0.50 probability of winning 10 points and a 0.50 probability of losing 10 points, and therefore an expected value of 0 . The alternative "experimental" gamble (colored blue) varied in the probability of winning (high, 0.60 vs low, 0.40 ), its magnitude of possible gains (large, 70 points vs small, 30 points), and its magnitude of possible losses (large, 70 points vs small, 30 points). These three variables were crossed to produce eight trial types with expected values that varied between -30 and 30 (Table 2).

The control and "experimental" gambles appeared randomly on the left or right of the visual displays. Participants were required to press " 1 " or " 2 " to indicate selection of the left or right gamble, respectively. Dependent measures included the following: (1) proportion of choices of the "experimental" gamble as a function of its probability of winning,
Table 1. Demographics and psychometrics of participants randomized to $7 \mathrm{~d}$ treatment with quetiapine $\mathrm{XL}(n=20)$ or matched placebo $(n=20)^{a}$

\begin{tabular}{lll}
\hline & Placebo & Quetiapine \\
\hline Gender (male:female) & $9: 11$ & $11: 9$ \\
Age & $23.57 \pm 0.71$ & $25.42 \pm 1.42$ \\
$\quad$ Verbal IQ & $113.0 \pm 1.19$ & $112.0 \pm 1.17$ \\
$\begin{array}{l}\text { State positive affect } \\
\quad \text { Baseline }\end{array}$ & $32.6 \pm 1.7$ & $34.2 \pm 1.5$ \\
$\quad$ Cognitive testing (day 8) & $32.1 \pm 1.6$ & $31.3 \pm 1.8$ \\
$\quad \begin{array}{l}\text { State negative affect } \\
\quad \text { Baseline }\end{array}$ & $12.1 \pm 0.6$ & $13.0 \pm 1.3$ \\
$\quad$ Cognitive testing (day 8) & $10.7 \pm 0.3$ & $11.6 \pm 0.6$ \\
$\quad \begin{array}{l}\text { State anxiety } \\
\quad \text { Baseline }\end{array}$ & $14.3 \pm 0.7$ & $15.0 \pm 0.9$ \\
$\quad$ Cognitive testing (day 8) & $13.4 \pm 0.7$ & $15.1 \pm 0.9$ \\
$\quad$ Baselindine & & \\
$\quad$ Cognitive testing (day 8) & $14.3 \pm 3.2$ & $14.3 \pm 3.4$ \\
\hline
\end{tabular}

$\bar{a}$ State positive and negative affect, state anxiety, and mood and energy levels are shown at baseline and at time of testing (day 8). Data are mean \pm SEM.

magnitudes of possible gains and possible losses; (2) proportion of choice of the "experimental" gamble as a function of its expected value; and (3) mean deliberation time (milliseconds) for these choices.

Finally, two extra trial types were included to assess the "reflection effect" (i.e., the non-normative biases of risk-averse and risk-seeking choices in dilemmas involving uncertain vs certain gains and uncertain vs certain losses, respectively) (Kahneman and Tversky, 1979; Schneider and Lopes, 1986). The first trial type was a "gains-only" trial, in which participants were asked to choose between a guaranteed win of 30 points and a gamble with a 0.50 probability of winning 60 points and a 0.50 probability of winning 0 points (Fig. $1 B$ ). Neither option involved losses. By contrast, the second type was a "losses-only" trial, in which participants were asked to choose between a guaranteed loss of 30 points and a gamble with a 0.50 probability of losing 60 points and a 0.50 probability of losing 0 points (Fig. 1C). Neither option involved gains. Within both "gains-only" and "losses-only" trial types, the expected values of each option were equal (30 points for "gains-only" options and -30 points for "losses-only" options).

Substantial evidence indicates that decision-makers usually exhibit a marked risk-aversion in the former case (i.e., they choose the guaranteed gain of 30 points) but marked risk-seeking behavior in the latter case (i.e., they choose the gamble with a 0.50 probability of losing 60 points and a 0.50 probability of losing 0 points) (Kahneman and Tversky, 1979). For the "gains-only" and "losses-only" trials, the dependent measures consisted of the following: (1) proportion of choices of the risky outcome and (2) mean deliberation time (milliseconds) for these choices.

These 10 trial types were presented in a pseudo-randomized order across 4 blocks of 20 trials; there were 8 repetitions of each "experimental" gamble and 8 repetitions of each of the "gains-only" and "losses-only" trial types. At the beginning of each block, participants were given 100 experimenter-defined points. After each choice, the computer provided visual and auditory feedback to indicate whether the participant had won or lost the selected gamble, and a revised points total was presented for $2 \mathrm{~s}$ before the next trial. Participants were asked to make choices that would increase their points score by as much as possible. At the end of each block, participants were given a final score for that block. The number of points accumulated across the 4 blocks was calculated as an additional dependent variable. These points had no monetary value, and participants' study reimbursement was independent of points scored on the risky decision-making task.

Statistical analysis. Between-group differences in the age, estimated verbal IQ, anxiety, mood, and energy levels of the quetiapine-treated and placebo-treated participants were tested by generalized linear models (GLMs) with the predictors: (1) quetiapine treatment (placebo as the reference) and (2) gender (male as the reference). Treatment-related changes in state positive and negative affect, anxiety, and mood and energy levels after quetiapine were assessed using GLMs with the predic- 


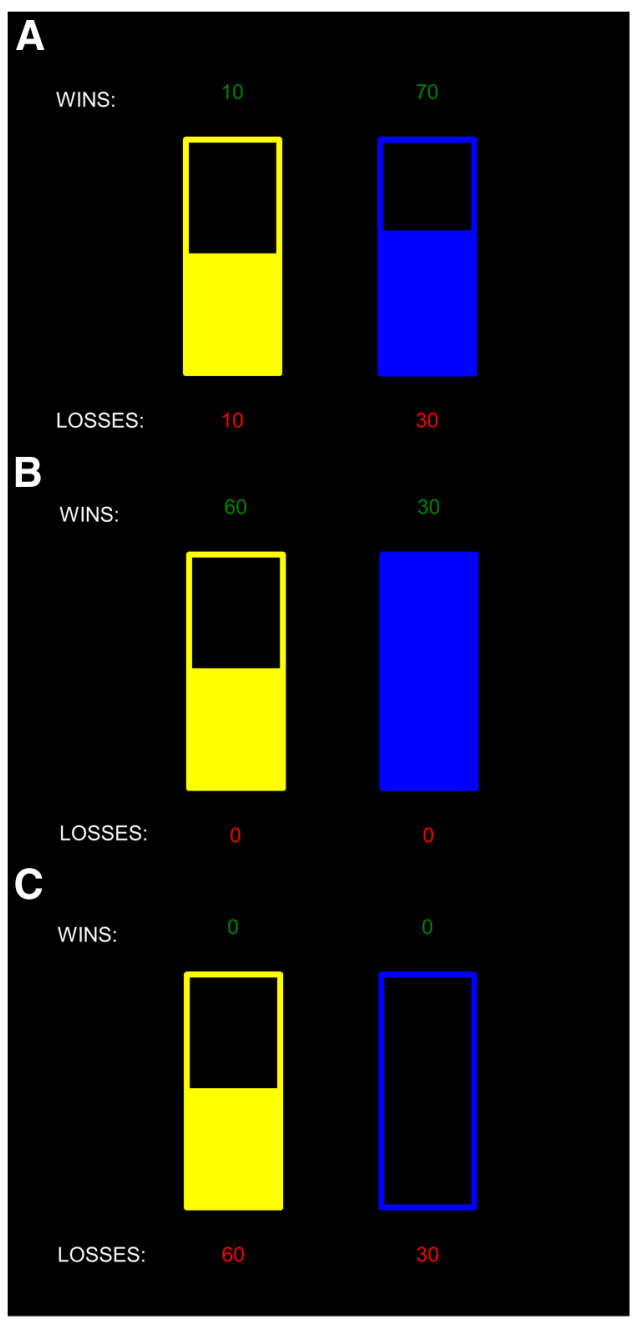

Figure 1. A, Example display from the risky choice task, consisting of an "experimental" gamble with a 0.60 probability of winning 70 points and a 0.40 probability of losing 30 points versus the control gamble with a 0.50 probability of winning 10 points and losing 10 points. $\boldsymbol{B}$, A "gains-only" trial consisting of a certain win of 30 points and a gamble with a 0.50 probability of winning 60 points or 0 points. C, A "losses-only" trial consisting of a certain loss of 30 points and a gamble with a 0.50 probability of losing of 60 points or 0 points.

Table 2. Proportionate choice of the eight trial types of "experimental" gambles resulting from the orthogonal combination of two levels of probability, magnitude of possible gains, and losses in our risky choice task administered to healthy adults who received $150 \mathrm{mg}$ quetiapine $\mathrm{XL}$ or placebo $^{a}$

\begin{tabular}{lllc}
\hline Probability of winning & Possible gains & Possible losses & Expected value \\
\hline High (0.60) & Large (70) & Large (70) & 14 \\
& & Small (30) & 30 \\
& Small (30) & Large (70) & -10 \\
& & Small (30)* & $6^{*}$ \\
Low (0.40) & Large (70) & Large (70) & -14 \\
& & Small (30) & 10 \\
& Small (30) & Large (70) & -30 \\
& & Small (30)* & $-6^{*}$ \\
\hline
\end{tabular}

a"Expected values" for the "experimental" gambles equal the sums of gains and losses, weighted by their probabilities of occurrence (Kahneman and Tversky, 2000), varying between -30 and 30, with a mean of 0 .

* "Experimental" gambles with low positive (6) or low negative (-6) expected values, in which proportionate choice departs from linear pattern.

tors: (1) quetiapine (placebo as the reference), (2) gender (male as the reference), and (3) time (pretreatment/baseline vs post-treatment).

For the risky decision-making task, (raw) proportionate choice of the "experimental" gamble was tested using a binomial GLM with the pre- dictors: (1) treatment (placebo as the reference), (2) gender (male as the reference), (3) high probability of winning (low as the reference), (4) large magnitude of possible gains (small as the reference), and (5) large magnitude of possible losses (small as the reference). Mean deliberation times (milliseconds) were analyzed using the equivalent standard, normal GLM. In follow-up analyses, proportionate choice of the "experimental" gambles with just the 3 lowest and the 3 highest expected values were analyzed using a GLM with the predictors: (1) treatment (placebo as the reference), (2) gender (male as the reference), (3) negative valence of the expected value (with positive as the reference), and (4) magnitude of expected value (30, 14 , and 10 as the reference).

Proportionate choice of the risky options in the "reflection effect" trials were tested using a binomial GLM with the following predictors: (1) treatment (placebo as the reference), (2) gender (male as the reference), (3) and "losses-only" trials ("gains-only" as the reference). Mean deliberation times (milliseconds) were analyzed with the equivalent standard, normal GLM.

Participant-level variance was modeled as random effects. Both random and fixed effects predictors and associated interactions are presented in the tables as the $\beta$-values, alongside their SEs and the derived $Z$-scores. The threshold for statistical significance was set at $Z>1.65(p<0.05)$. Selected post hoc tests were completed with standard two-sample $t$ tests. Indicators of the magnitude of betweentreatment differences (quetiapine vs placebo) (MD) are shown, along with $95 \%$ CIs.

\section{Results}

\section{Participant characteristics and subjective responses}

The quetiapine-treated and placebo-treated participants were closely matched for age and estimated verbal IQ ( $\beta=2.88(2.18)$ and $\beta=-0.12(2.30)$, respectively; Table 1$)$. State-positive affect and -negative affect, state anxiety, and scores on the Befindlichkeit Scale of Mood and Energy did not change markedly between baseline and the end of the treatment period $(-12.44(6.18)<$ $\beta s<0.78(3.02))$. Quetiapine produced no significant changes in any of these measures compared with placebo $(-3.83(4.08)<$ $\beta \mathrm{s}<15.86(8.34))$, and there were no significant treatmentrelated differences in state affect, state anxiety, or scores on Befindlichkeit Scale of Mood and Energy at the time of cognitive testing $(0.30(1.44)<\beta s<7.75(5.84))$. Finally, there were no significant differences in the effects of quetiapine over placebo treatment in male compared with female participants on any of the above tests $(-19.92(11.79)<\beta s<1.75(5.76))$.

\section{Risky decision-making task}

Participants who were treated with quetiapine accumulated slightly higher total scores by the end of the risky choice task compared with those who were treated with placebo $(345 \pm 42 \mathrm{vs}$ $302 \pm 37)$; this difference was not significant (MD, 43; 95\% CI, -71 to $157 ; \beta=51.62(77.53))$.

\section{Proportionate choice as a function of probability of winning,} magnitude of possible gains, and magnitude of possible losses Participants chose the "experimental" gamble more frequently when its probability of winning was high rather than low $(0.67 \pm$ 0.03 vs $0.25 \pm 0.03 ; \beta=4.14(0.50) ; Z=8.34 ; p<0.0001)$ and when its possible gains were large compared with small $(0.54 \pm$ 0.02 vs $0.38 \pm 0.02 ; \beta=2.33(0.42) ; Z=5.52 ; p<0.0001)$. Participants also chose the "experimental" gamble less frequently when its possible losses were large compared with small $(0.33 \pm$ 0.03 vs $0.58 \pm 0.02 ; \beta=-1.05(0.41) ; Z=-2.63 ; p<0.01)$. These effects combined in a significant three-way interaction between the probability of winning, the magnitude of possible gains, and magnitude of possible losses $(\beta=3.36(0.89) ; Z=3.78$; $p<0.0005)$, reflecting participants' use of expected value when making their risky choices. 

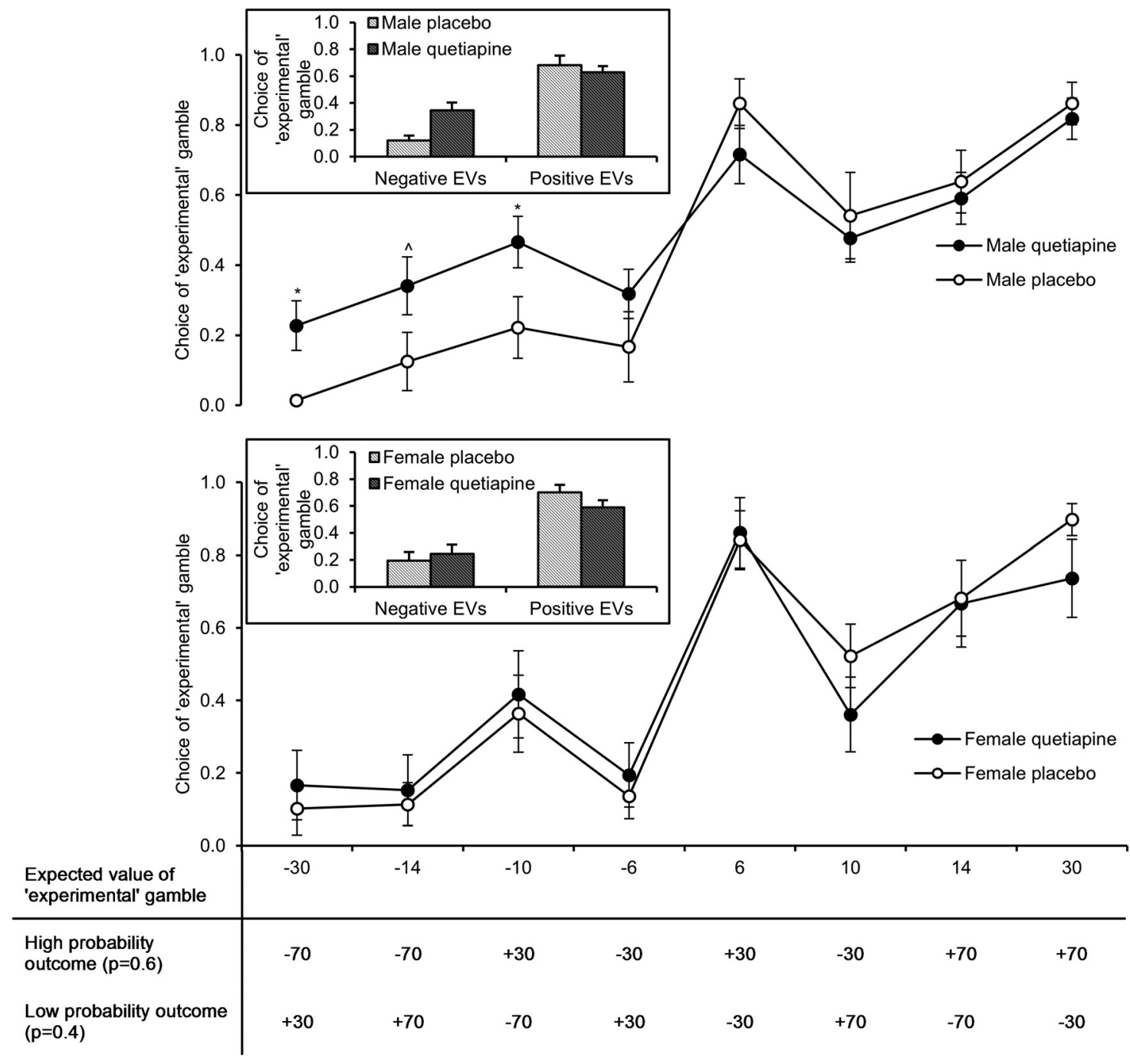

Figure 2. Proportionate choice of the "experimental" over the control gamble for male and female participants after $7 \mathrm{~d}$ treatment with $150 \mathrm{mg}$ of quetiapine XL and placebo as a function of expected value. Insets, Proportionate choice of the "experimental" gambles with negative or positive expected values in quetiapine-treated and placebo-treated participants. Error bars indicate SEM. ${ }^{*} p<0.05 ; \wedge p<0.1$.

Overall, there was a modest increase in the choice of the "experimental" gamble in the quetiapine-treated participants compared with the placebo-treated participants $(0.47 \pm 0.03$ vs $0.44 \pm 0.03$, respectively; $\mathrm{MD}, 0.03 ; 95 \% \mathrm{CI},-0.05$ to $-0.11 ; \beta=1.32(0.54) ; Z=2.44 ; p<0.01)$. This drug effect was modulated by the expected value of the "experimental gamble," as reflected in the significant four-way interaction between quetiapine, the probability of winning, and the magnitudes of the possible gains and losses $(\beta=-3.31$ (1.12); $Z=$ $-2.96, p<0.005)$, and was most strongly expressed in male compared with female participants in a reliable interaction between these four factors and gender $(\beta=3.87(1.53) ; Z=$ 2.53, $p<0.05$; Fig. 2).

Although choice of the "experimental" gamble tended to increase with the expected value $(\beta=0.42(0.05) ; Z=9.37$, $p<0.0001)$, these choices were markedly diminished with expected values of -6 but then increased with expected values of 6 (Fig. 2), reflecting the interactions between the probability of winning, and the magnitudes of possible gains and losses noted above. Further tests, excluding trials with the expected values of -6 and 6 , demonstrated that quetiapine increased choice of "experimental" gambles with negative expected val- ues (Fig. 2, inset; MD, 0.22; 95\% CI, 0.07-0.38), but not positive expected values $(\mathrm{MD},-0.05 ; 95 \% \mathrm{CI},-0.23$ to 0.12 ; $\beta=-1.38(0.46) ; Z=-3.07, p<0.005)$ in male participants. Quetiapine treatment significantly increased choice of "experimental" gambles with expected values of $-30\left(t_{(18)}=2.67\right.$, $p=0.02)$ and $-10\left(t_{(18)}=2.14, p=0.046\right)$, with a trend toward significance when the expected value was $-14\left(t_{(18)}=\right.$ $1.821, p=0.085)$.

Quetiapine had no comparable effects upon choices of "experimental gamble" with negative expected values (MD, 0.05; $95 \% \mathrm{CI},-0.15$ to 0.25 ; Fig. 2, inset) relative to positive expected values (MD, $-0.11 ; 95 \% \mathrm{CI},-0.29$ to 0.06$)$ in the female participants $(\beta=-0.73(0.46))$.

\section{Deliberation times}

Participants' deliberation times were not substantially increased or decreased when the probability of winning associated with the "experimental" gamble was high compared with when it was low $(2256 \pm 122 \mathrm{~ms}$ vs $2230 \pm 129 \mathrm{~ms} ; \beta=$ 26(227)). Similarly, deliberation times were not much altered when the magnitude of gains was large compared with small $(2242 \pm 131 \mathrm{~ms}$ vs $2244 \pm 120 \mathrm{~ms} ; \beta=319(227))$ or when the 
Table 3. Mean deliberation time (ms) of participants randomized to $7 \mathrm{~d}$ treatment with quetiapine XL $(n=20)$ or treatment with a matched placebo $(n=20)$, as a function of high versus low probability of winning, large versus small possible gains, and large versus small possible losses ${ }^{a}$

\begin{tabular}{|c|c|c|c|c|c|c|}
\hline & \multicolumn{2}{|c|}{ Probability of winning } & \multicolumn{2}{|c|}{ Size of possible gains } & \multicolumn{2}{|c|}{ Size of possible losses } \\
\hline & High & Low & Large & Small & Large & Small \\
\hline Placebo & $2242 \pm 171$ & $2218 \pm 174$ & $2225 \pm 181$ & $2235 \pm 167$ & $2202 \pm 168$ & $2258 \pm 173$ \\
\hline Quetiapine & $2269 \pm 179$ & $2242 \pm 195$ & $2258 \pm 193$ & $2253 \pm 178$ & $2241 \pm 172$ & $2271 \pm 193$ \\
\hline
\end{tabular}

${ }^{a}$ Data are mean \pm SEM.

magnitude of losses was large compared with small (2221 \pm $119 \mathrm{~ms}$ vs $2264 \pm 128 \mathrm{~ms} ; \beta=-247(164)$ ). Deliberation times did not change reliably with the expected value of the "experimental" gamble $(\beta=130(454))$.

Overall, participants treated with quetiapine did not differ in their deliberation times compared with the placebo-treated participants $(2256 \pm 180 \mathrm{~ms}$ vs $2230 \pm 167 \mathrm{~ms}$; MD, 26; $95 \% \mathrm{CI}$, -472 to $523 ; \beta=22(407))$. There were no treatment effects involving deliberation time as a function of the probability of winning or magnitudes of gains or losses associated with the "experimental" gamble $(-149(317)<\beta$ s $<413(275)$; Table 3$)$. Finally, quetiapine did not differentially influence deliberation times as a function of expected value $(\beta=634(633))$ overall, or in males compared with female participants $(\beta \mathrm{s}=-493(871))$.

\section{The "reflection effect": "gains-only" versus "losses-only" trials}

\section{Proportionate choice}

Consistent with previous reports of the "reflection effect" (Kahneman and Tversky, 2000), participants chose the risky outcome more often on the "losses-only" trials (offering a certain loss of 30 points or a 0.50 probability of a 60 points loss or no loss) than on the "gains-only" trials (offering a certain gain of 30 points or a 0.50 probability of a 60 points gain or no gain $)(0.78 \pm 0.04$ vs $0.29 \pm 0.04)(\beta=1.38(0.39) ; Z=3.53$, $p<0.0005)$.

These shifts between risk-averse and risk-seeking choices were slightly enhanced after quetiapine treatment $(0.84 \pm 0.06$ vs $0.28 \pm 0.05)$ compared with placebo treatment $(0.72 \pm 0.06$ vs $0.30 \pm 0.08)(\mathrm{MD}, 0.15 ; 95 \% \mathrm{CI},-0.11$ to $0.41 ; \beta=1.24(0.55)$, $Z=2.25, p<0.05)$. However, the effects of quetiapine treatment upon the "reflection effect" were not significantly different in the males compared with female participants $(\beta=0.95(0.88))$.

\section{Deliberation time}

Participants were reliably slower to make choices on "lossesonly" compared with "gains-only" trials $(3117 \pm 230 \mathrm{~ms}$ vs $1811 \pm 149 \mathrm{~ms} ; \beta=1549(365) ; Z=4.24, p<0.0001)$. However, this delay while making predominantly risk-seeking choices was not much altered after quetiapine $(2827 \pm 297 \mathrm{~ms}$ vs $1713 \pm 209$ ms) compared with placebo treatment (3407 $\pm 347 \mathrm{~ms}$ vs $1910 \pm$ $217 \mathrm{~ms}$ ) (MD, $-383 \mathrm{~ms} ; 95 \% \mathrm{CI},-1197$ to $431 \mathrm{~ms} ; \beta=$ 355(587)).

\section{Discussion}

Our results demonstrate that $7 \mathrm{~d}$ treatment with quetiapine altered the use of expected value while making risky decisions involving explicit reinforcement cues in male compared with female participants. The pharmacology of quetiapine involves dual antagonism of both $5-\mathrm{HT}_{2 \mathrm{~A}}$ and $\mathrm{D}_{2}$ receptors, whereas its active metabolite, norquetiapine, is an antagonist at $5-\mathrm{HT}_{2 \mathrm{C}}$ receptors. Overall, the effects of quetiapine treatment upon choices that offered explicit reinforcement cues were associated with more frequent selections of gambles with negative expected values in male participants (i.e., selections that would tend to be disadvantageous over the longer-term according to normative choice models) (Kahneman and Tversky, 2000).

Quetiapine- and placebo-treated (male and female) participants were closely matched for age and estimated verbal IQ, making it unlikely that our results can be attributed easily to relevant preexisting differences across genders. Similarly, there were no signs that quetiapine differentially influenced state-positive and -negative affect, or anxiety, taken at baseline and at cognitive testing $7 \mathrm{~d}$ later in males compared with $\mathrm{fe}$ males. Quetiapine can produce marked sedation, typically at doses higher than those used here (Miller, 2004; Calabrese et al., 2005). However, at $150 \mathrm{mg}$, the extended-release quetiapine used in this experiment did not influence deliberation times as a function of the probability of winning, magnitude of possible gains, or possible losses associated with the "experimental" gamble. Therefore, there is little evidence that our male participants' ability to make complete the risky choice task after quetiapine treatment can be attributed to sedation or diminished motivation.

Previous research suggests that manipulations of monoamine function, for example, through phenylalanine and tyrosine depletion (de Wit et al., 2012) or tryptophan depletion (Sambeth et al., 2007), can produce larger changes in the cognitive and affective function of healthy female adults rather than male adults. Therefore, research will need to determine precisely why quetiapine had a more substantial impact upon the risky choices of males. Possible mediating mechanisms include gender-specific differences in the structure of the monoamine neuromodulatory systems (Wong et al., 2012), the expression of $5-\mathrm{HT}_{2 \mathrm{~A}}$ receptors (Fehr et al., 2000), and $\mathrm{D}_{2}$ receptors (Kaasinen et al., 2001), as well as functional differences in the dopaminergic and serotonergic receptor systems that might influence aspects of decision-making function (Nishizawa et al., 1997). Finally, gender differences in both $5-\mathrm{HT}_{2 \mathrm{~A}}$ and $\mathrm{D}_{2}$ receptor expression and activity are subject to the differential influence of sex steroids in males compared with females (Fink et al., 1999; Zhang et al., 1999).

Alternatively, other evidence suggests that differences in risk attitudes might reflect underlying gender-specific substrates (Sapienza et al., 2009; but see Joel and Tarrasch, 2010). Observations from neurological patients and fMRI experiments in healthy adults suggest that decision-making functions are lateralized toward the right hemisphere in males, but toward the left hemisphere in females, perhaps reflecting different cognitive strategies (holistic/gestalt-type processing vs analytic, verbal) across the genders (Bolla et al., 2004; Tranel et al., 2005). Therefore, the heightened sensitivity of male participants over female participants to the effects of short-term quetiapine may reflect the operation of action selection mechanisms that are differentially sensitive to altered $\mathrm{D}_{2}$ and $5-\mathrm{HT}_{2 \mathrm{~A}}$ activity.

Notwithstanding these uncertainties, our findings complement previous demonstrations that attentional processing of 
explicit reinforcement signals while making risky decisions is sensitive to manipulation of serotonin and dopamine activity. Tryptophan depletion reduced attention toward gain cues in the same task as the one used here, suggesting that serotonin plays a role in the attentional processing of positive reinforcement signals (Rogers et al., 2003). On the other hand, tryptophan supplementation, which might be expected to enhance serotonin activity, increased choices associated with small negative expected values (Murphy et al., 2009). Finally, phenylalanine and tyrosine depletion impaired attention toward loss cues, suggesting that dopamine activity, in addition to its role in action-outcome computations for positive reinforcers, influences the processing of explicit punishment cues in the context of uncertain choice outcomes (Scarna et al., 2005).

The current findings add to the above picture in three ways. First, complementing previous reports that quetiapine (weakly) attenuates the reward value of powerful reinforcers, such as cocaine (Gallo et al., 2010), our data demonstrate that the antagonism of $5-\mathrm{HT}_{2 \mathrm{~A}}$ and (to a more limited extent) $\mathrm{D}_{2}$ receptors, following treatment with quetiapine, can interfere with the tendency to use expected value when selecting between actions. Of course, quetiapine's pharmacology is complex; its metabolite, norquetiapine, blocks $5-\mathrm{HT}_{2 \mathrm{C}}$ receptor activity and potentiates catecholamine activity within prefrontal cortex (Pira et al., 2004). Further research is needed to elucidate properly which of quetiapine's pharmacological properties, alone or in combination, mediate the altered use of expected value in risky choices.

Second, our findings demonstrate that short-term treatment with quetiapine enhances the attractiveness of disadvantageous behavioral options. Previously, we found that small single doses of the $\mathrm{CB}_{1}$ receptor agonist, $\Delta$-9-tetrahydrocannabinol, increased the selection of the control gamble in our risky choice task, suggesting preference for actions with zero expected value (Rogers et al., 2007). By contrast, here, quetiapine increased the choice of gambles whose expected values were negative and would have produced aggregate losses over the longer term (Kahneman and Tversky, 2000), suggesting that cannabinoid and monoamine receptor activity can produce complementary effects upon the use of expected value when people make risky choices.

Relatedly, the observation that quetiapine increased choice of "experimental" gambles with negative expected values, without markedly influencing choice of gambles with positive expected values, indicates that quetiapine did not simply flatten the broadly positive relationship between expected value and choice. Current theories of serotonin postulate that activity of the dorsal raphe nucleus supports the predictive coding of aversive outcomes (Cools et al., 2008) to facilitate the inhibition of ongoing behavior (Dayan and Huys, 2008; Crockett et al., 2009). $D_{2}$ receptor activity (within the indirect striatopallidal pathway) also supports the learning triggered by bad choice outcomes (Frank and O'Reilly, 2006; Frank et al., 2007). Our findings indicate that treatment with an atypical antipsychotic drug with strong antagonist properties at $5-\mathrm{HT}_{2 \mathrm{~A}}$ receptors, but weak antagonist properties at $\mathrm{D}_{2}$ receptors, enhances healthy adults' preference for actions that might (theoretically) be disadvantageous over the longer term (Kahneman and Tversky, 2000).

Third, our data suggest that, although quetiapine treatment influences the attention toward reinforcement signals when making risky choices, it has marginal effects upon at least some salient non-normative aspects of choice. Previ- ously, we found that administration of tryptophan attenuated shifts between risk-averse and risk-seeking choices in the reflection effect (Murphy et al., 2009). Here, we found that quetiapine tended to enhance (modestly) these shifts, without this being significantly more marked in males compared with females. Therefore, although quetiapine promoted the selection of actions with negative values in male participants more than female participants, there is little evidence that it reliably enhanced shifts between risk-averse and risk-seeking choices in one gender more than the other.

Our conclusions must be confined to actions in healthy male adults, but they suggest clinical implications and pose interesting questions. First, quetiapine is an effective treatment for bipolar depression (Bauer et al., 2009) and can also stabilize mood from manic states in bipolar patients (Bowden et al., 2005; Calabrese et al., 2005), so contributing to maintenance treatment strategies (Suppes et al., 2009). These therapeutic properties may be linked to the phenomena described here and the capacity of quetiapine to modulate the processing of reinforcement signals (Gallo et al., 2010). Speculatively, individuals with bipolar disorder may show an exaggerated attention toward explicit signals of the magnitudes of good and bad choice outcomes (Chandler et al., 2009), reflecting their altered incentive salience (Berridge and Aldridge, 2008). Quetiapine's therapeutic effects may involve the attenuation of this attentional capture or the diminishing of incentive salience of reinforcement signals, potentially normalizing the evaluation of choice outcomes to stabilize behavior.

The present results may also be relevant to our understanding of how antipsychotics influence other elements of psychotic illnesses (Kapur et al., 2005). Quetiapine has been used to treat negative symptoms in schizophrenia (Tandon, 2003), possibly restoring the neural signals within prefrontal regions elicited by emotional material (Stip et al., 2005). It also has antipsychotic properties as indicated by diminishing conditioned avoidant responses in animal models (Wadenberg et al., 2001). At a clinical level, quetiapine may facilitate the extinction of avoidant responses by enhancing the likelihood of selecting actions with negative expected values, allowing affected individuals (e.g., patients) to learn that such actions are not uniformly associated with bad outcomes or that the outcomes themselves, when they are delivered, are not as aversive as feared. In this way, the shift toward choices with negative expected values that could be predicted to be disadvantageous in healthy nonclinical individuals may turn out to be a benefit in clinical populations.

In conclusion, these data demonstrate that short-term treatment with quetiapine altered the way that healthy adult males used explicit signals about large and small gains, and large and small losses, to increase the choice of gambles with negative expected values. Our findings suggest that blockade of $5-\mathrm{HT}_{2 \mathrm{~A}}$ and, to a lesser extent, $\mathrm{D}_{2}$ receptors by atypical antipsychotic drugs may alter the use of explicit reinforcement cues during risky decision-making.

\section{References}

Abler B, Greenhouse I, Ongur D, Walter H, Heckers S (2008) Abnormal reward system activation in mania. Neuropsychopharmacology 33:22172227. CrossRef Medline

Bauer M, Pretorius HW, Constant EL, Earley WR, Szamosi J, Brecher M (2009) Extended-release quetiapine as adjunct to an antidepressant in patients with major depressive disorder: results of a randomized, placebocontrolled, double-blind study. J Clin Psychiatry 70:540-549. CrossRef Medline 
Bayer HM, Glimcher PW (2005) Midbrain dopamine neurons encode a quantitative reward prediction error signal. Neuron 47:129-141. CrossRef Medline

Berridge KC, Robinson TE (1998) What is the role of dopamine in reward: hedonic impact, reward learning, or incentive salience? Brain Res Rev 28:309-369. CrossRef Medline

Berridge KC, Aldridge JW (2008) Decision utility, the brain, and pursuit of hedonic goals. Soc Cogn 26:621-646. CrossRef Medline

Bolla KI, Eldreth DA, Matochik JA, Cadet JL (2004) Sex-related differences in a gambling task and its neurological correlates. Cereb Cortex 14:12261232. CrossRef Medline

Boureau YL, Dayan P (2011) Opponency revisited: competition and cooperation between dopamine and serotonin. Neuropsychopharmacology 36:74-97. CrossRef Medline

Bowden CL, Grunze H, Mullen J, Brecher M, Paulsson B, Jones M, Vågerö M, Svensson K (2005) A randomized, double-blind, placebo-controlled efficacy and safety study of quetiapine or lithium as monotherapy for mania in bipolar disorder. J Clin Psychiatry 66:111-121. CrossRef Medline

Calabrese JR, Keck PE Jr, Macfadden W, Minkwitz M, Ketter TA, Weisler RH, Cutler AJ, McCoy R, Wilson E, Mullen J (2005) A randomized, doubleblind, placebo-controlled trial of quetiapine in the treatment of bipolar I or II depression. Am J Psychiatry 162:1351-1360. CrossRef Medline

Chandler RA, Wakeley J, Goodwin GM, Rogers RD (2009) Altered riskaversion and risk-seeking behavior in bipolar disorder. Biol Psychiatry 66:840-846. CrossRef Medline

Cools R, Robinson OJ, Sahakian B (2008) Acute tryptophan depletion in healthy volunteers enhances punishment prediction but does not affect reward prediction. Neuropsychopharmacology 33:2291-2299. CrossRef Medline

Cools R, Nakamura K, Daw ND (2011) Serotonin and dopamine: unifying affective, activational, and decision functions. Neuropsychopharmacology 36:98-113. CrossRef Medline

Crockett MJ, Clark L, Robbins TW (2009) Reconciling the role of serotonin in behavioral inhibition and aversion: acute tryptophan depletion abolishes punishment-induced inhibition in humans. J Neurosci 29:11993-11999. CrossRef Medline

Cunningham KA, Bubar MJ, Anastasio NC (2010) The serotonin 5-HT2C receptor in medial prefrontal cortex exerts rheostatic control over the motivational salience of cocaine-associated cues: new observations from preclinical animal research. Neuropsychopharmacology 35:2319-2321. CrossRef Medline

Cunningham KA, Fox RG, Anastasio NC, Bubar MJ, Stutz SJ, Moeller FG, Gilbertson SR, Rosenzweig-Lipson S (2011) Selective serotonin 5-HT(2C) receptor activation suppresses the reinforcing efficacy of cocaine and sucrose but differentially affects the incentive-salience value of cocaine- vs sucrose-associated cues. Neuropharmacology 61:513-523. CrossRef Medline

Daw ND, Kakade S, Dayan P (2002) Opponent interactions between serotonin and dopamine. Neural Netw 15:603-616. CrossRef Medline

Dayan P, Huys QJ (2008) Serotonin, inhibition, and negative mood. PLoS Comput Biol 4:e4. CrossRef Medline

de Wit S, Standing HR, Devito EE, Robinson OJ, Ridderinkhof KR, Robbins TW, Sahakian BJ (2012) Reliance on habits at the expense of goaldirected control following dopamine precursor depletion. Psychopharmacology (Berl) 219:621-631. CrossRef Medline

Fehr C, Szegedi A, Anghelescu I, Klawe C, Hiemke C, Dahmen N (2000) Sex differences in allelic frequencies of the 5-HT2C Cys23Ser polymorphism in psychiatric patients and healthy volunteers: findings from an association study. Psychiatr Genet 10:59-65. CrossRef Medline

Fink G, Sumner B, Rosie R, Wilson H, McQueen J (1999) Androgen actions on central serotonin neurotransmission: relevance for mood, mental state and memory. Behav Brain Res 105:53-68. CrossRef Medline

Frank MJ, O'Reilly RC (2006) A mechanistic account of striatal dopamine function in human cognition: psychopharmacological studies with cabergoline and haloperidol. Behav Neurosci 120:497-517. CrossRef Medline

Frank MJ, Samanta J, Moustafa AA, Sherman SJ (2007) Hold your horses: impulsivity, deep brain stimulation, and medication in parkinsonism. Science 318:1309-1312. CrossRef Medline

Gallo A, Lapointe S, Stip E, Potvin S, Rompré PP (2010) Quetiapine blocks cocaine-induced enhancement of brain stimulation reward. Behav Brain Res 208:163-168. CrossRef Medline
Harmer CJ, Shelley NC, Cowen PJ, Goodwin GM (2004) Increased positive versus negative affective perception and memory in healthy volunteers following selective serotonin and norepinephrine reuptake inhibition. J Psychiatry 161:1256-1263. CrossRef Medline

Hollerman JR, Schultz W (1998) Dopamine neurons report an error in the temporal prediction of reward during learning. Nat Neurosci 1:304-309. CrossRef Medline

Joel D, Tarrasch R (2010) The risk of a wrong conclusion: on testosterone and gender differences in risk aversion and career choices. Proc Natl Acad Sci U S A 107:E19; author reply E20. CrossRef Medline

Kaasinen V, Någren K, Hietala J, Farde L, Rinne JO (2001) Sex differences in extrastriatal dopamine d(2)-like receptors in the human brain. Am J Psychiatry 158:308-311. CrossRef Medline

Kahneman D, Tversky A (1979) Prospect theory: an analysis of decisions under risk. Econometrica 47:263-291. CrossRef

Kahneman D, Tversky A (2000) Choices values and frames. Cambridge, United Kingdom: Cambridge UP.

Kapur S, Mizrahi R, Li M (2005) From dopamine to salience to psychosis: linking biology, pharmacology and phenomenology of psychosis. Schizophr Res 79:59-68. CrossRef Medline

McClure SM, Daw ND, Montague PR (2003) A computational substrate for incentive salience. Trends Neurosci 26:423-428. CrossRef Medline

Miller DD (2004) Atypical antipsychotics: sleep, sedation, and efficacy. Prim Care Companion J Clin Psychiatry 6 [Suppl 2]:3-7. CrossRef Medline

Montague PR, Hyman SE, Cohen JD (2004) Computational roles for dopamine in behavioural control. Nature 431:760-767. CrossRef Medline

Murphy SE, Longhitano C, Ayres RE, Cowen PJ, Harmer CJ, Rogers RD (2009) The role of serotonin in nonnormative risky choice: the effects of tryptophan supplements on the "reflection effect" in healthy adult volunteers. J Cogn Neurosci 21:1709-1719. CrossRef Medline

Nelson HE (1982) National Adult Reading Test Manual. Windsor, UK: NFER-Nelson.

Nishizawa S, Benkelfat C, Young SN, Leyton M, Mzengeza S, de Montigny C, Blier P, Diksic M (1997) Differences between males and females in rates of serotonin synthesis in human brain. Proc Natl Acad Sci U S A 94:5308 5313. CrossRef Medline

Pira L, Mongeau R, Pani L (2004) The atypical antipsychotic quetiapine increases both noradrenaline and dopamine release in the rat prefrontal cortex. Eur J Pharmacol 504:61-64. CrossRef Medline

Robinson TE, Berridge KC (1993) The neural basis of drug craving: an incentive-sensitization theory of addiction. Brain Res Brain Res Rev 18: 247-291. CrossRef Medline

Rogers RD (2011) The roles of dopamine and serotonin in decision making: evidence from pharmacological experiments in humans. Neuropsychopharmacology 36:114-132. CrossRef Medline

Rogers RD, Tunbridge EM, Bhagwagar Z, Drevets WC, Sahakian BJ, Carter CS (2003) Tryptophan depletion alters the decision-making of healthy volunteers through altered processing of reward cues. Neuropsychopharmacology 28:153-162. CrossRef Medline

Rogers RD, Wakeley J, Robson PJ, Bhagwagar Z, Makela P (2007) The effects of low doses of $\delta-9$ tetrahydrocannabinol on reinforcement processing in the risky decision-making of young healthy adults. Neuropsychopharmacology 32:417-428. CrossRef Medline

Roiser JP, Stephan KE, den Ouden HE, Barnes TR, Friston KJ, Joyce EM (2009) Do patients with schizophrenia exhibit aberrant salience? Psychol Med 39:199-209. CrossRef Medline

Sambeth A, Blokland A, Harmer CJ, Kilkens TO, Nathan PJ, Porter RJ, Schmitt JA, Scholtissen B, Sobczak S, Young AH, Riedel WJ (2007) Sex differences in the effect of acute tryptophan depletion on declarative episodic memory: a pooled analysis of nine studies. Neurosci Biobehav Rev 31:516-529. CrossRef Medline

Sapienza P, Zingales L, Maestripieri D (2009) Gender differences in financial risk aversion and career choices are affected by testosterone. Proc Nat Acad Sci U S A 106:15268-15273. CrossRef Medline

Scarna A, McTavish SF, Cowen PJ, Goodwin GM, Rogers RD (2005) The effects of a branched chain amino acid mixture supplemented with tryptophan on biochemical indices of neurotransmitter function and decision-making. Psychopharmacology (Berl) 179:761-768. CrossRef Medline

Schneider S, Lopes L (1986) Reflection in preferences under risk: who and when may suggest why. J Exp Psychol 12:535. 
Schultz W (2010) Dopamine signals for reward value and risk: basic and recent data. Behav Brain Funct 6:24. CrossRef Medline

Sheehan DV, Lecrubier Y, Sheehan KH, Amorim P, Janavs J, Weiller E, Hergueta T, Baker R, Dunbar GC (1998) The Mini-International Neuropsychiatric Interview (M.I.N.I.): the development and validation of a structured diagnostic psychiatric interview for DSM-IV and ICD-10. J Clin Psychiatry 59 [Suppl 20]:22-33; quiz 34-57.

Spielberger CD, Gorsuch RL, Lushene RD (1970) STAI manual. Palo Alto, CA: Consulting Psychologists.

Stip E, Fahim C, Mancini-Marïe A, Bentaleb LA, Mensour B, Mendrek A, Beauregard M (2005) Restoration of frontal activation during a treatment with quetiapine: an fMRI study of blunted affect in schizophrenia. Prog Neuropsychopharmacol Biol Psychiatry 29:21-26. CrossRef Medline

Suppes T, Vieta E, Liu S, Brecher M, Paulsson B (2009) Maintenance treatment for patients with bipolar I disorder: results from a North American study of quetiapine in combination with lithium or divalproex (trial 127). Am J Psychiatry 166:476-488. CrossRef Medline

Tandon R (2003) Improvement without impairment: a review of clinical data for quetiapine in the treatment of schizophrenia. J Clin Psychopharmacol 23:S15-S20. CrossRef Medline
Tranel D, Damasio H, Denburg NL, Bechara A (2005) Does gender play a role in functional asymmetry of ventromedial prefrontal cortex? Brain 128:2872-2881. CrossRef Medline

von Zerssen D, Strian F, Schwarz D (1974) Evaluation of depressive states, especially in longitudinal studies. Mod Probl Pharmacopsychiatry 7:189_ 202. Medline

Wadenberg MG, Soliman A, VanderSpek SC, Kapur S (2001) Dopamine D2 receptor occupancy is a common mechanism underlying animal models of antipsychotics and their clinical effects. Neuropsychophamacology 25: 633-641. CrossRef Medline

Watson D, Clark LA, Tellegen A (1988) Development and validation of brief measures of positive and negative affect: the PANAS scales. J Pers Soc Psychol 54:1063-1070. CrossRef Medline

Wong KK, Müller ML, Kuwabara H, Studenski SA, Bohnen NI (2012) Gender differences in nigrostriatal dopaminergic innervation are present at young-to-middle but not at older age in normal adults. J Clin Neurosci 19:183-184. CrossRef Medline

Zhang L, Ma W, Barker JL, Rubinow DR (1999) Sex differences in expression of serotonin receptors (subtypes $1 \mathrm{~A}$ and $2 \mathrm{~A}$ ) in rat brain: a possible role for testosterone. Neuroscience 94:251-259. CrossRef Medline 